\title{
Comunicação
}

[Communication]

\section{Sazonalidade como fator interferente na composição físico-química e avaliação microbiológica de queijos coloniais}

\author{
[Seasonality as an interfering factor on the chemical composition and \\ microbiological quality of colonial cheeses] \\ D.F. Oliveira, C.E.C. Bravo, I.B. Tonial
}

Universidade Tecnológica Federal do Paraná - Campus Francisco Beltrão, PR

O queijo, por apresentar relevantes teores de lipídios, proteínas, minerais e vitaminas, é considerado um alimento completo e importante na alimentação humana (ABIQ, 2005).

Em estudo sobre o comportamento dos consumidores de produtos artesanais, Silveira (2006) constatou que os queijos artesanais representam uma parcela significativa de aceitação por parte dos consumidores. $\mathrm{O}$ autor comenta ainda que, dentre os interferentes que podem contribuir para a variação da composição físico-química dos queijos coloniais, encontram-se os fatores climáticos, a sazonalidade forrageira, o balanceamento da dieta alimentar e a qualidade do leite, que acabam afetando a fisiologia do animal.

De acordo com Fagan (2006), a falta de critérios de qualidade e de padronização da matéria-prima e das técnicas de processamento pode ocasionar produtos bem diversos em relação à sua composição e muitas vezes de baixa qualidade microbiológica. $\mathrm{O}$ fato de o queijo colonial ser elaborado a partir de leite cru e não sofrer processo de maturação, o torna um veículo frequente de patógenos de origem alimentar, podendo oferecer riscos de toxi-infecções alimentares (Kottwitz e Guimarães, 2003). Sendo assim, o presente estudo teve como objetivo verificar a interferência das estações primavera e verão na qualidade físico-química e a incidência de microrganismos patogênicos em queijos coloniais produzidos no sudoeste do Paraná. Foram coletadas de quatro diferentes produtores amostras de queijos coloniais em supermercados e feiras livres. As amostras foram transportadas em caixas térmicas, lacradas e analisadas em laboratórios da Universidade Tecnológica Federal do Paraná, campus Francisco BeltrãoPR.

As análises microbiológicas foram realizadas assim que as amostras chegaram aos laboratórios da universidade. Para a determinação de coliformes termotolerantes, Staphylococcus coagulase positiva e Salmonella $\mathrm{sp}$. seguiu-se a metodologia definida pela Instrução Normativa do Ministério da Agricultura, Pecuária e Abastecimento (MAPA) n $n^{\circ}$ 62/2003 (Brasil, 2003).

Os teores de umidade, cinzas e proteína foram determinados de acordo com as técnicas da AOAC (1997). Os teores de lipídios totais foram analisados de acordo com a metodologia de Bligh e Dyer (1959), sendo o índice de acidez determinado conforme descrito no manual do Instituto Adolfo Lutz (IAL, 1985).

Os valores da composição centesimal foram submetidos à análise de variância (ANOVA) a $5 \%$ de probabilidade, pelo teste de Tukey, por meio do software Statistica, versão 7.0 (STATSOFT INC, 2004).

Observou-se, pelos resultados obtidos (Tab. 1 e 2) que os queijos apresentaram baixo conteúdo de proteínas, sendo que os produzidos durante o verão apresentaram maiores percentuais de proteínas em relação aos produzidos na primavera. Para Flemming et al. (2004) isto pode

Recebido em 5 de março de 2011

Aceito em 31 de outubro de 2011

E-mail: deborafolhe@hotmail.com 
ser devido ao excesso de coalho na massa, o que possibilita maior proteólise, ou ainda em decorrência da maior disponibilidade de pastagens nessa época do ano, estas, geralmente, ricas em proteínas e gorduras.

Tabela 1. Valores dos teores de umidade, cinzas, lipídios totais, proteínas e índice de acidez obtidos em queijos produzidos na primavera

\begin{tabular}{lcccc} 
Teores & Amostra - A & Amostra - B & Amostra - C & Amostra - D \\
\hline Proteínas(\%) & $5,11 \pm 0,01 \mathrm{a}$ & $5,42 \pm 0,40 \mathrm{ab}$ & $5,01 \pm 0,54^{\mathrm{a}}$ & $5,69 \pm 0,48 \mathrm{~b}$ \\
CV $(\%)$ & 0,19 & 7,38 & 10,78 & 8,43 \\
Umidade $(\%)$ & $68,07 \pm 0,05 \mathrm{a}$ & $68,88 \pm 0,05 \mathrm{~b}$ & $70,56 \pm 0,03 \mathrm{c}$ & $70,15 \pm 0,30 \mathrm{~d}$ \\
CV $(\%)$ & 0,07 & 0,07 & 0,04 & 0,42 \\
Cinzas(\%) & $3,42 \pm 0,01 \mathrm{a}$ & $3,62 \pm 0,05 \mathrm{~b}$ & $4,13 \pm 0,01 \mathrm{c}$ & $2,77 \pm 0,04 \mathrm{~d}$ \\
CV $(\%)$ & 0,29 & 1,38 & 0,24 & 1,44 \\
LT(\%) & $24,28 \pm 0,10 \mathrm{a}$ & $21,49 \pm 0,40 \mathrm{ab}$ & $20,93 \pm 0,67 \mathrm{~b}$ & $22,30 \pm 0,17 \mathrm{ab}$ \\
CV(\%) & 0,41 & 1,86 & 3,20 & 0,76 \\
\%Ác.Lático(\%) & $0,94 \pm 0,06 \mathrm{a}$ & $0,93 \pm 0,01 \mathrm{~b}$ & $0,24 \pm 0,01 \mathrm{c}$ & $1,05 \pm 0,01 \mathrm{~d}$ \\
CV(\%) & 6,38 & 1,07 & 4,16 & 0,95 \\
\hline
\end{tabular}

Os resultados são médias em quatro replicatas com as respectivas estimativas do desvio-padrão. Valores na mesma linha seguidos de letras iguais não diferem entre si ( $p>0,05)$, [Análise de variância - ANOVA e Teste de Tukey]. $\mathrm{CV}=$ coeficiente de variação $=($ desvio-padrão/média $) \times 100$.

Tabela 2. Valores dos teores de umidade, cinzas, lipídios totais, proteínas e acidez obtidos em queijos produzidos no verão

\begin{tabular}{lcccc}
\hline Teores & Amostra - A & Amostra - B & Amostra - C & Amostra - D \\
\hline Proteínas(\%) & $6,65 \pm 0,23 \mathrm{a}$ & $6,94 \pm 0,09 \mathrm{a}$ & $5,30 \pm 0,06 \mathrm{~b}$ & $7,04 \pm 0,01 \mathrm{a}$ \\
CV(\%) & 3,45 & 1,29 & 1,13 & 0,14 \\
Umidade $(\%)$ & $73,22 \pm 0,09 \mathrm{a}$ & $63,34 \pm 0,46 \mathrm{~b}$ & $79,88 \pm 0,13 \mathrm{c}$ & $68,46 \pm 0,12 \mathrm{~d}$ \\
CV(\%) & 0,12 & 0,72 & 0,16 & 0,17 \\
Cinzas(\%) & $2,79 \pm 0,09 \mathrm{a}$ & $5,72 \pm 0,21 \mathrm{~b}$ & $2,81 \pm 0,11^{\mathrm{a}}$ & $4,89 \pm 0,07 \mathrm{c}$ \\
CV(\%) & 3,22 & 3,67 & 3,91 & 1,43 \\
LT $(\%)$ & $17,29 \pm 0,11 \mathrm{a}$ & $24,12 \pm 0,37 \mathrm{~b}$ & $12,06 \pm 0,25 \mathrm{c}$ & $20,22 \pm 0,09 \mathrm{~d}$ \\
CV(\%) & 0,63 & 1,53 & 2,07 & 0,45 \\
\%Ác.Lático(\%) & $0,79 \pm 0,01 \mathrm{a}$ & $0,92 \pm 0,01 \mathrm{~b}$ & $0,31 \pm 0,01 \mathrm{c}$ & $1,15 \pm 0,03 \mathrm{~d}$ \\
CV(\%) & 1,26 & 1,08 & 3,22 & 2,60 \\
\hline
\end{tabular}

Os resultados são médias em quatro replicatas com as respectivas estimativas do desvio-padrão. Valores na mesma linha seguidos de letras iguais não diferem entre si (p>0,05), [Análise de variância - ANOVA e Teste de Tukey]. $\mathrm{CV}=$ coeficiente de variação $=($ desvio-padrão/média $) \times 100$.

Os queijos analisados apresentaram teores de umidade acima de $55 \%$, por isso podem ser classificados como queijos de muito alta umidade (Brasil, 1996). De acordo com Silveira (2006), a diferença nos teores de umidade pode ser reflexo do tipo de prensagem, do tamanho dos queijos, do teor de sal e do tempo de maturação.

De acordo com o Ministério da Agricultura e Abastecimento (Brasil, 1996), ao apresentarem teores de gordura entre 10,0 e $24,9 \%$, os queijos analisados podem ser considerados magros. Para Fagan (2006), a dieta ofertada ao animal é o principal fator que influencia nos teores de lipídios e de minerais do queijo.
Segundo Kottwitz e Guimarães (2003), a adoção de boas práticas de fabricação tem reduzido os riscos de contaminação nos alimentos, aumentando a qualidade de vida dos consumidores.

Por meio dos resultados das análises microbiológicas, observou-se que das 32 amostras de queijos analisadas $50 \%$ apresentaram coliformes termotolerantes, $100 \%$ Staphyloccocus coagulase positiva e $12,5 \%$ Salmonella sp., podendo ser consideradas impróprias para o consumo por estarem fora dos padrões microbiológicos estabelecidos para queijos (Brasil, 2001). Estes microrganismos, quando presentes nos alimentos, são indicadores 
de condições inadequadas de higiene, podendo causar ao homem toxi-infecções alimentares (Kottwitz e Guimarães, 2003). Com base nos resultados do estudo, observou-se que a sazonalidade interferiu na composição físicoquímica dos queijos coloniais analisados durante as estações primavera e verão, os quais se encontravam impróprios para o consumo humano por apresentarem contagens de
Staphyloccocus coagulase positiva acima do limite estabelecido pela legislação brasileira para queijos.

Palavras-chave: queijo colonial, sazonalidade, fisiologia animal, análises físico-químicas e microbiológicas

\begin{abstract}
The influence of seasonality on chemical composition of cheese produced during different seasons, was verified as well as their microbiological quality. A total of 32 samples of colonial cheeses produced in the southwestern Paraná were analyzed. Although the study could be thoroughly not completed, the chemical results showed significant variations $(p<0.05)$ among the cheeses produced during the spring and summer seasons. The microbiological results indicated that 50\%, 100\% and $12.5 \%$ of the samples were contaminated with fecal coliforms, Staphylococcus coagulase positive and Salmonella spp., so at odds with the microbiological standards established by the legislation.
\end{abstract}

Keywords: colonial cheese, Seasonality, physical-chemical analysis, microbiological analysis

\section{REFERÊNCIAS}

ABIQ. Benefícios nutricionais dos queijos. Associação Brasileira das Indústrias de Queijo, 2005. Disponível em: <http://www.abiq.com.br/>. Acessado em: 23 fev. 2010.

AOAC - Association of Official Analytical Chemists. Official methods of analysis. 16.ed. Gaitherburg, 1997. v.2, cap. 32, p.1-43.

BLIGH, E.G.; DYER.; W.J. A rapid method of total lipid estraction and purification. Canad. J. Bioch. v.37, p.911-17, 1959.

BRASIL. Ministério da Agricultura, Pecuária e Abastecimento - MAPA. Instrução Normativa ${ }^{\circ} 62$ de 26 de agosto de 2003. Oficializa os Métodos Analíticos Oficiais para Análises Microbiológicas para Controle de Produtos de Origem Animal e Água. Diário Oficial da União, Brasília, DF, 18 de set, 2003.

BRASIL. Ministério da Agricultura, Pecuária e Abastecimento - MAPA. Secretaria Nacional de Inspeção de Produtos de Origem Animal. Portaria n. 146, de 07 de março de 1996. Regulamentos Técnicos de Identidade e Qualidade dos Produtos Lácteos.. Diário Oficial da União, Brasília, DF, 11 mar. 1996.

BRASIL. Agência Nacional de Vigilância Sanitária ANVISA. Resolução de Diretoria Colegiada (RDC) n. 12, de 02 de janeiro de 2001. Aprova o Regulamento Técnico sobre padrões microbiológicos para alimentos. Diário Oficial da União, Brasília, 10 de janeiro, 2001. Seção 1, p.45-53.
FAGAN, E.P. Fatores ambientais e de manejo sobre a composição química, microbiológica e toxicológica do leite produzido em duas granjas produtoras de leite tipo A no estado do Paraná. 2006. 123f. Tese (Doutorado em Zootecnia). Universidade Estadual de Maringá, Maringá.

FLEMMING, J.S.; BRUM, J.V.F.; FREITAS, J.R.S. et al. Composição da forragem e os parâmetros de gordura do creme de leite e da manteiga. Arch. Vet. Sci. v.9, p.31-34, 2004.

INSTITUTO Adolfo Lutz. Métodos químicos e físicos para análise de alimentos. Normas Analíticas do Instituto Adolfo Lutz. v.1, 3.ed. São Paulo: IMESP, 1985. p.13-14.

KOTTWITZ, L.B.M.; GUIMARÃES, I.M. Avaliação microbiológica de queijos coloniais produzidos no Estado do Paraná. Hig. Alim., v.17, p.77-80, 2003.

SILVEIRA, P.R.C da. Riscos alimentares em uma sociedade de risco: compreendendo o comportamento do consumidor de alimentos artesanais. 2006. $88 \mathrm{f}$. Tese (Doutorado em Ciências Humanas) Universidade Federal de Santa Catarina, Florianópolis.

STATSOFT INC. Statistica data analysis system version 7.0. Tulsa: Statsoft Inc., 2004. 